\title{
Effect of job satisfaction on burnout among physicians: A survey study in urban public medical institutions in Hubei province, China
}

\author{
Yimin Zhang ${ }^{1,2}$, Li Shen ${ }^{3}$, Jiquan Lou ${ }^{1}$, Yuan Jing ${ }^{1}$, Yong Lu ${ }^{4,5}$, Hong Liang ${ }^{1,2}$, Xueshan Feng $^{4,6^{*}}$ \\ ${ }^{1}$ Pudong Institute for Health Development, Shanghai, China \\ ${ }^{2}$ School of Social Development and Public Policy, Fudan University, Shanghai, China \\ ${ }^{3}$ Business School, University of Shanghai for Science and Technology, Shanghai, China \\ ${ }^{4}$ Department of Social Medicine, School of Public Health, Fudan University, Shanghai, China \\ ${ }^{5}$ Medical Institutions and Administration Center of Pudong New Area, Shanghai, China \\ ${ }^{6}$ Key Laboratory of Public Health Security, Ministry of Education, Shanghai, China; ${ }^{*}$ Corresponding Author: xsfeng@,fudan.edu.cn
}

Received 17 August 2012; revised 17 September 2012; accepted 2 October 2012

\begin{abstract}
Objectives: Chinese physicians are being loaded with the enormous psychological pressure and so tend to be susceptible to burnout. Little is known on the relationship between job satisfaction and burnout for physicians from urban public medical institutions. We aim to describe the degree of burnout and evaluate the impact of job satisfaction on burnout. Methods: A cross-

personal accomplishment $\left(R^{2}=0.40\right)$ significantly. Conclusions: Occupational burnout, especially emotional exhaustion and depersonalization, is common and serious among Chinese physicians. Several, but not all dimensions of job satisfaction, which prove to have predictive effects on burnout, should be paid more attention to in order to improve physicians' psychological health.
\end{abstract} sectional survey was conducted in March 2010 in Hubei province, central China. The job satisfaction and burnout instruments were obtained by modifying the Chinese Physicians' Job Satisfaction Questionnaire and the Chinese Maslach Burnout Inventory, respectively. Such statistical methods as one-way ANOVA, Pearson correlation coefficient and GLM-univariate were employed. Results: The observed mean and burnout incidence on emotional exhaustion (3.45 \pm $0.75,66.99 \%)$ and depersonalization (3.56 \pm 0.76 , $68.64 \%$ ) were high, but reduced personal accomplishment $(2.18 \pm 0.56,5.79 \%)$ was low. The distribution of the degree of overall burnout was: $3.2 \%$ (severe), $48.2 \%$ (moderate), $35.4 \%$ (mild) and $13.2 \%$ (zero). Less the development level of urban area and higher the grade of medical institution was, more severe physicians' burnout was. Job-itself satisfaction $\left(b_{1}=-0.166, b_{2}=\right.$ $-0.056)$, job rewards satisfaction $\left(b_{1}=-0.084, b_{2}=\right.$ $-0.150)$ and medical practicing environment satisfaction $\left(b_{1}=-0.096, b_{2}=-0.319\right)$ were identified as significant negative predictors of emotional exhaustion $\left(R^{2}=0.35\right)$ and also of depersonalization $\left(R^{2}=0.46\right)$. Only the job-itself satisfaction $\left(b_{3}=-0.355\right)$ contributed to reduced
Keywords: Effect; Job Satisfaction; Burnout; Physicians

\section{INTRODUCTION}

Accompanied with the enhanced awareness of civil rights and increasing treatment expectations, more and more medical disputes between physicians and patients have been taking place in China and also around the world. This cause contributes to the phenomenon that a large number of physicians are loaded with enormous psychological burden, in addition, with the information asymmetry in medical market, the trust from patients to physicians become less. In this context, Chinese physicians, superficially attributed to the root of various contradictions in the healthcare system, tend to be extremely susceptible to occupational burnout, which may be higher than the professionals in other fields. According to some empirical studies [1,2], it is very likely for burnout as an adverse attitude to generate some negative influences not only on their physical and mental health but on quality of health services provided and working productivity. Thus, more importance should be attached to the urgent issue at present.

Burnout is a comprehensive concept to describe demoralisation, disillusionment and exhaustion in human 
service workers, firstly proposed by Freudenburger in clinical psychology [3]. It is conceptualized as a process that occurs over time, rather than a state. In the light of the famous three-dimension model defined by Maslach [4], burnout stemming from continuous working pressures that are not relieved promptly, is composed of the following three dimensions: emotional exhaustion, depersonalization and reduced personal accomplishment. Emotional exhaustion involves feelings of being emotionally overextended and exhausted by one's work due to excessive psychological demands, resulting in a loss of energy weakness. Depersonalization refers to the development of impersonal interaction and unfeeling attitudes toward those being serviced and loss of idealism at work. The feeling of reduced personal accomplishment refers to a declined sense of achievement and competence with regard to one's work with clients. Besides, the job strain model identifies job characteristics as the principal source of psychological strain in the workplace, proposing that this results from the combination of high job demands and low job control, and has been extended to include lack of support as a third source of job strain: this has become known as the Demand-Control-Support model $[5,6]$. Then, a range of predominant theoretical models on burnout were further advanced, including the Conservation of Resources Model and the Job Demands Resources Model [7,8]. In fact, the studies with burnout exactly originated from healthcare professionals, and were gradually adopted among other helping professions.

Additionally, a number of descriptive studies in connection with burnout so far had been conducted among clinical physicians such as anesthetists, radiologists, urologists, pediatricians and oncologists in many countries, showing that there were different degrees of burnout symptom for employees in this profession [8-12]. However, the previous studies have mostly focused on certain branches of medical practice, and there is little information about the integrated situation of occupational burnout among the population of physicians covering all specialties [13]. In spite of several surveys carried out among Chinese physicians in the 2010s [14,15], data is still scarce and we need to provide more documents on burnout for these subjects, especially from urban public medical institutions, which were recognized as the most important area in a new round of medical reform in China.

Some summaries have indicated that burnout is usually associated with a variety of factors found in the individual, organizational and social aspects $[16,17]$. The correlation between job satisfaction and burnout has been confirmed in health care $[18,19]$, and more recent studies have noted that a few dimensions of job satisfaction could significantly anticipate burnout [19-21]. Instead of this opinion, other studies support the view that burnout may result in consequences on job satisfaction of physi- cians $[22,23]$. Therefore, it is seen that the relationship between them is still controversial, and moreover isn't known in the case of Chinese physicians. Under the attitude theory revealing connections between these two components in psychology [24], it has already been accepted that cognitive appraisal for a specific substance could yield corresponding emotional reaction. So our hypothesis in this study was as follows: job satisfaction, placing extra emphasis on the cognition and appraisal element of job attitude, could generate predictive effects on burnout, concentrating on the emotion element of job attitude.

The purpose of this paper is to describe the degree of occupational burnout and identify whether there were variations among different groups; and to estimate effect of job satisfaction on occupational burnout on the basis of the correlation examined among Chinese physicians from urban public medical institutions.

\section{METHOD}

\subsection{Participants and Sampling}

Hubei province in central China, where the number of doctors per thousand population $(1.61 \%, 2010)$ is average through the whole country, was determined as the source site of sample. Inclusion criteria for participants eligible for admittance to the study include the following three points: owning a practicing qualified certificate file, signing a formal employment contract with serviced health institutions, and willing to participate in this survey. These subjects without practicing qualified certificate or not building employment relationship with the surveyed institutions (e.g. internship, pursuing further education temporally) should be excluded. Based on the official information, the number of physicians in actual population was 12,568 , accounting for $45 \%$ of the total of physicians from this province. From the data of an initial investigation $(n=276)$ undertaken in one city, Hubei province, the sample size in formal survey was calculated to be no fewer than 1445 individuals for estimating the population mean of several burnout dimensions by the related formulas. A method of multistage stratified cluster random sampling was adopted to acquire the study sample. The socioeconomic development level was used as stratification standard at the first stage to randomly select three urban areas (Wuhan, Shiyan, and Jingmen, representing high, middle and low level, respectively) from 13 cities of the province; then, the grade of medical institutions was used as stratification standard in each sample city at the second stage to randomly select 67 public medical institutions ( 8 third-grade institutions, 12 second-grade institutions and 47 firstgrade institutions, representing high, middle and low referral levels of medical technology and scale, respec- 
tively); at last, the sample group was selected from these institutions by simple random sampling at the third stage. This study had been approved by the ethics committee of school of public health, Fudan University, and therefore performed in accordance with the 1964 Declaration of Helsinki. All participants were voluntary, and expressed informed consent prior to their inclusion.

\subsection{Measuring Instruments}

A five-page questionnaire was produced, consisting of three parts along with a covering letter outlining the survey objective and reply methods.

- Part 1 included the sociodemographic information of gender, age, marital status, education background, employment mode, average monthly income (US\$), technical position, department, and years of service.

- An assessment of job satisfaction in Part 2 was mainly made using the Chinese Physicians' Job Satisfaction Questionnaire (CPJSQ) with a total of 62 items compiled [25], and well validated in a subsequent largescale study [26]. Unfortunately, this Questionnaire can only be available in the Chinese Journal Fulltext Database (CJFD). However, some modifications, as a result of the practice of pilot survey, were made in order to further improve the quality of this instrument. Three items even more attached to the scope of social support network and another two items about scientific research and clinical teaching work not suitable for physicians from the first-grade medical institutions were deleted, while an important new item on the reasonableness of performance appraisal for public hospitals was increased. At last, the survey instrument through the above revisions consisted of 58 specific items, which participants were asked to rate on a five-point Likert scale from 1 (strongly disagree) to 5 (strongly agree), according to how they perceived each aspect had contributed to their work satisfaction.

Exploratory factor analysis (EFA) of this instrument on the pilot sample indicated that five factors were extracted, including job-itself satisfaction, estimated by 10 items; work environment satisfaction, estimated by 13 items; job rewards satisfaction, estimated by 13 items; organizational management satisfaction, estimated by 11 items; and medical practicing environment satisfaction, estimated by 11 items. Then, confirmatory factor analysis (CFA) on the formal sample revealed that a five-factor measurement Model F could be ideally supported (GFI, NFI, CFI, IFI >0.9, RMSEA $=0.075$, RMR $=$ $0.024, \operatorname{lambda}(x) \geq 0.55)$. This showed that this instrument had good construct validity. The Cronbach $\alpha$ coefficient was 0.829 for the job-itself satisfaction subscale, 0.885 for the work environment satisfaction subscale, 0.916 for the job-rewards satisfaction subscale, 0.924 for the organizational management satisfaction subscale, 0.798 for the medical practicing environment satisfaction subscale, all of which demonstrated a high level of reliability. The score of each job-satisfaction subscale was computed to an average score.

- Burnout in Part 3 was estimated using the Chinese Maslach Burnout Inventory (CMBI), with a total of 15 items developed and verified as valid [27]. Only the Likert scale was changed from 7-point to 5-point (ranging from " 1 , never" to " 5 , daily") due to the following two reasons: this can keep consistent with Part 2 on the scale, which is conductive to analyze their relationships concisely; it seemed to be very difficult for the respondents in the pilot survey to distinguish the answers of 7-point scale. This inventory suitable for the cultural background of China, can also be available in the Chinese Journal Full-text Database (CJFD).

EFA of the CMBI on the pilot sample also divided burnout into three dimensions: emotional exhaustion, depersonalization and reduced personal accomplishment. Each dimension was equally assessed by five items, and the percentages of explained variance by these three principal factors amounted to be $57.31 \%$. Furthermore, CFA of this instrument on the formal sample revealed that a three-factor measurement Model Q could be appropriately supported by the investigation data (GFI, NFI, CFI, IFI $>0.9$, RMSEA $=0.068$, RMR $=0.047$, lambda $(\mathrm{x}) \geq 0.59$ ). It was seen by the cross-sample validation that this instrument had good construct validity. A reliability test showed that the Cronbach $\alpha$ coefficient was 0.802 for motional exhaustion, 0.715 for depersonalization, and 0.864 for reduced personal accomplishment, which were acceptable at least.

The average scores of different dimensions on burnout were calculated, on the basis of which burnout occurrence on each dimension was obtained in terms of cut-off made ahead of time. Usually, more than 3 average scores in the five-point scales were used as the watershed to identify its occurrence. Additionally, the degree of overall burnout for an individual was compositely defined in accordance with burnout occurrences on these three dimensions as the following four ranks: severe burnout if burnout occurrences on all of the three dimensions were present, moderate burnout if burnout occurrences on any two of the three dimensions were present, mild burnout if burnout occurrence on only one of the three dimensions was present, and zero burnout if burnout occurrence on none of the three dimensions was present.

\subsection{Data Collection}

A cross-sectional survey was carried out in 67 public medical institutions of three sample cities in March 2010. Participants were anonymously surveyed with the selfadministered questionnaire. Each participant was told 
about the important values of this study for improving their interests, and simultaneously presented a small memento to raise response rate as high as possible. Completed questionnaires were regained under detailed inspections on the spot by investigators, who had no access to the subsequent material arrangement. Data was accepted for the final analysis after invalid questionnaires (46) were rejected in accordance with the following principles: sociodemographic data incomplete; more than three missing values among all items; and responses overcentralized which may lead to systematic errors in the measurement.

\subsection{Statistical Analysis}

Data analysis was performed with SPSS for Windows Version 16.0. The threshold of statistical significance was set at $P<0.05$ (two-tailed). First, descriptive statistics were involved to estimate mean score $(\mathrm{X} \pm \mathrm{S})$ and detectable incidence $(\%)$ on each dimension of burnout, as well as frequency distribution (\%) of the degree of overall burnout. Next, comparisons were made among groups from three urban areas with different development levels and public medical institutions with different grades by one-way ANOVA test and Kruskal-Wallis test. In addition, Pearson correlation coefficients were calculated to determine the associations between burnout syndrome and job satisfaction. One thing which needs to be pointed out was that these variables can be deemed as continuous through averaging corresponding items, and also meet normal distribution via hypothesis testing. Finally, GLMUnivariate analysis was employed to examine whether job satisfaction factors could significantly affect each di- mension of occupational burnout regarded as dependent variables, and also used to assess the changes in significance and explained variances (Adj. $\mathrm{R}^{2}$ ) by building progressive models, especially when these sociodemographic characteristics were controlled as additional independent variables.

\section{RESULTS}

\subsection{Sociodemographic Characteristics of Study Group}

Of the 1600 physicians surveyed in the three urban areas, 1497 (93.6\%, response rate) responded. Of those responses, 1451 valid questionnaires were finally acquired, yielding an effectiveness rate of $96.9 \%$. Of the study sample, 501 doctors were from Wuhan city, with 476 from Shiyan city, and 474 from Jingmen city; 594 doctors were from the third-grade medical institutions, with 489 from the second-grade medical institutions, and 368 from the first-grade medical institutions.

The sociodemographic characteristics of study group were shown in Table $\mathbf{1}$. It was specially seen from it that 440 doctors $(30 \%)$ received low levels of education (junior college and below), most of which had worked in the first- and second-grade medical institutions and provided basic medical services and public health services within the fixed communities, and that a total of 164 (almost 12\%) were medical assistants, whose technical titles had not usually been identified since these doctors entered organizations for less than two years after their graduations, or they were restricted by the threshold of education background.

Table 1. Sociodemographic data of the sample group participated in this study $(n=1451)$.

\begin{tabular}{|c|c|c|c|c|c|}
\hline Characteristics & Category & NO. (\%) & Characteristics & Category & NO. (\%) \\
\hline \multirow{2}{*}{ Gender } & Male & $960(66.2)$ & \multirow{5}{*}{ Technical title } & Medical assistant & $164(11.3)$ \\
\hline & Female & $491(33.8)$ & & Resident physician & $466(32.1)$ \\
\hline \multirow{3}{*}{ Age (years) } & $31-40$ & $540(37.2)$ & & Associate chief physician & $270(18.6)$ \\
\hline & $41-50$ & $240(16.6)$ & & Chief physician & $74(5.1)$ \\
\hline & $\geq 51$ & $115(7.9)$ & & Internal medicine & \\
\hline \multirow{2}{*}{ Marital status } & Married & $1127(77.7)$ & \multirow{8}{*}{ Department } & Surgery & $382(26.3)$ \\
\hline & Technical secondary school & $143(9.9)$ & & Pediatrics & $49(3.4)$ \\
\hline \multirow{5}{*}{$\begin{array}{l}\text { Education } \\
\text { background }\end{array}$} & Junior college & $297(20.5)$ & & $\begin{array}{l}\text { Ophthalmology and } \\
\text { otorhinolaryngology }\end{array}$ & $122(8.4)$ \\
\hline & Bachelor & $787(54.2)$ & & Prevention and care & $32(2.2)$ \\
\hline & Master & $164(11.3)$ & & Medical laboratory & $162(11.2)$ \\
\hline & Doctor & $60(4.1)$ & & Gynaecology \& obstetrics & $132(9.1)$ \\
\hline & $\leq 5$ & $549(37.9)$ & & Anesthesiology & $110(7.6)$ \\
\hline \multirow{2}{*}{ Years of service } & $6-15$ & $604(41.6)$ & & Emergency & $50(3.4)$ \\
\hline & $16-25$ & $233(16.0)$ & \multirow{5}{*}{$\begin{array}{c}\text { Average income } \\
\text { /month (\$) }\end{array}$} & $\leq 152$ & $43(3.0)$ \\
\hline \multirow{4}{*}{ Employment mode } & $\geq 26$ & $65(4.5)$ & & $153-304$ & $537(37.0)$ \\
\hline & Formal & $1192(82.2)$ & & $305-456$ & $429(29.6)$ \\
\hline & Casual & $259(17.8)$ & & $457-608$ & $257(17.7)$ \\
\hline & & & & $\geq 609$ & $185(12.7)$ \\
\hline
\end{tabular}




\subsection{Descriptive Statistics and Comparisons on Burnout}

As evidenced by Table 2, the observed mean of emotional exhaustion was 3.45 , with 3.56 on depersonalization and 2.18 on reduced personal accomplishment among the sampled physicians. Under the criteria defined previously, reported burnout occurrences were detected in $66.99 \%$ of them on the emotional exhaustion dimension, in $68.64 \%$ on the depersonalization dimension, and in merely $5.79 \%$ on the reduced personal accomplishment dimension. Besides, Table 2 showed that there were significant differences in other two dimensions of burnout except reduced personal accomplishment among these groups from the three urban areas representing different levels of development $\left(\mathrm{F}_{\mathrm{EE}}=9.75, P<0.01 ; \mathrm{F}_{\mathrm{DP}}=21.65\right.$, $\left.P<0.01 ; \mathrm{F}_{\mathrm{RPA}}=1.68, P>0.1\right)$, and also significant differences in all three dimensions of burnout among these groups with regard to public medical institutions with different grades $\left(\mathrm{F}_{\mathrm{EE}}=31.56, P<0.01 ; \mathrm{F}_{\mathrm{D}}=53.55, P<\right.$ $\left.0.01 ; \mathrm{F}_{\mathrm{RPA}}=5.62, P<0.01\right)$.

Table 3 indicated that the frequency distribution of the degree of overall burnout, founded on situation of burnout occurrences on the three dimensions above, is 47 (3.2\%) with severe burnout, 699 (48.2\%) with moderate burnout, 513 (35.4\%) with mild burnout, and 192 (13.2\%) with zero burnout among the study population. It could be brought to light that the percentage of physicians in moderate and severe burnout, in contrast to that in zero and mild burnout, gradually increased from Wuhan city with high-level development to Jingmen city with lowlevel development, and there was significant difference among these groups from the three urban areas with different development levels $\left(\chi_{\mathrm{H}}^{2}=35.72, P<0.01\right)$; that the percentage of physicians in moderate and severe burnout, not the same as that in zero and mild burnout, however, visibly declined from the third-grade public medical institutions to the first-grade public medical institutions, and there was significant difference among these groups from public medical institutions with different grades. $\left(\chi_{\mathrm{H}}^{2}=\right.$ 70.64, $P<0.01)$.

\subsection{Correlation between Burnout Syndrome and Job Satisfaction}

When the correlation between burnout syndrome and job satisfaction was examined among physicians, Table 4 showed that all of three dimensions on burnout were significantly negatively related to each job-satisfaction subscale $(P<0.01)$. It was clear that there were larger correlation coefficients between emotional exhaustion and medical practicing environment satisfaction $(r=-0.283)$, and job-itself satisfaction $(r=-0.267)$, while depersonalization was more closely correlated with medical practicing environment satisfaction $(r=-0.595)$, and job rewards satisfaction $(r=-0.450)$. Of these job-satisfaction

Table 2. Statistical descriptions ( $\overline{\mathrm{X}} \pm \mathrm{S}, \%$ ) and comparisons among groups on three dimensions of burnout.

\begin{tabular}{|c|c|c|c|c|c|c|c|c|c|c|}
\hline & \multicolumn{3}{|c|}{ Development level of urban area } & \multirow{2}{*}{$\mathbf{F}$} & \multicolumn{3}{|c|}{ Grade of public medical institution } & \multirow{2}{*}{$\mathbf{F}$} & \multirow{2}{*}{$\begin{array}{c}\text { Total } \\
\text { sample }\end{array}$} & \multirow{2}{*}{$\begin{array}{l}\text { Burnout } \\
\text { incidence }\end{array}$} \\
\hline & High level & Medium level & Low level & & Third grade & Second grade & First grade & & & \\
\hline $\mathrm{EE}$ & $3.33 \pm 0.75$ & $3.47 \pm 0.74$ & $3.54 \pm 0.77$ & $9.75^{* *}$ & $3.61 \pm 0.76$ & $3.40 \pm 0.75$ & $3.23 \pm 0.68$ & $31.56^{* *}$ & $3.45 \pm 0.75$ & $66.99 \%$ \\
\hline DP & $3.43 \pm 0.77$ & $3.51 \pm 0.77$ & $3.74 \pm 0.73$ & $21.65^{* *}$ & $3.76 \pm 0.73$ & $3.54 \pm 0.75$ & $3.25 \pm 0.72$ & $53.55^{* *}$ & $3.56 \pm 0.76$ & $68.64 \%$ \\
\hline
\end{tabular}

${ }^{* *} P<0.01$. Abbreviations: EE: Emotional Exhaustion; DP: Depersonalization; RPA: Reduced Personal Accomplishment.

Table 3. Frequency distribution (\%) and comparisons on the degree of overall burnout.

\begin{tabular}{|c|c|c|c|c|c|c|}
\hline & & Zero burnout & Mild burnout & $\begin{array}{c}\text { Moderate } \\
\text { burnout }\end{array}$ & $\begin{array}{c}\text { Severe } \\
\text { burnout }\end{array}$ & $\begin{array}{c}\text { Kruskal-Wallis } \\
\text { test }(\mathbf{H})\end{array}$ \\
\hline \multirow{3}{*}{$\begin{array}{c}\text { Development level } \\
\text { of urban area }\end{array}$} & High level (Wuhan) & 16.0 & 41.1 & 40.7 & 2.2 & \multirow{3}{*}{$\chi^{2}=35.72^{* *}$} \\
\hline & Medium level (Shiyan) & 12.6 & 38.7 & 45.0 & 3.8 & \\
\hline & Low level (Jingmen) & 11.0 & 25.9 & 59.3 & 3.8 & \\
\hline \multirow{3}{*}{$\begin{array}{c}\text { Grade of public } \\
\text { medical institution }\end{array}$} & Third grade & 9.4 & 28.8 & 57.4 & 4.4 & \multirow{3}{*}{$\chi^{2}=70.64^{* *}$} \\
\hline & Second grade & 13.9 & 33.3 & 50.3 & 2.5 & \\
\hline & First grade & 18.5 & 48.6 & 30.4 & 2.4 & \\
\hline \multicolumn{2}{|c|}{ Total sample } & 13.2 & 35.4 & 48.2 & 3.2 & - \\
\hline
\end{tabular}

${ }^{* *} P<0.01$. 
Table 4. Pearson correlation coefficients $(r)$ between burnout syndrome and job satisfaction.

\begin{tabular}{|c|c|c|c|}
\hline & \multicolumn{3}{|c|}{ Burnout syndrome dimensions } \\
\hline & Emotional exhaustion & Depersonalization & Reduced personal accomplishment \\
\hline Job-itself satisfaction & $-0.267^{* *}$ & $-0.284^{* *}$ & $-0.574^{* *}$ \\
\hline Work environment satisfaction & $-0.208^{* *}$ & $-0.375^{* *}$ & $-0.271^{* *}$ \\
\hline Job rewards satisfaction & $-0.244^{* *}$ & $-0.450^{* *}$ & $-0.235^{* *}$ \\
\hline Organizational management satisfaction & $-0.166^{* *}$ & $-0.319^{* *}$ & $-0.249^{* *}$ \\
\hline Medical practicing environment satisfaction & $-0.283^{* *}$ & $-0.595^{* *}$ & $-0.180^{* *}$ \\
\hline
\end{tabular}
${ }^{* *} P<0.01$.

subscales, job-itself satisfaction displayed the highest correlation with reduced personal accomplishment $(r=$ $-0.574)$.

\subsection{Effect of Job Satisfaction on Occupational Burnout among Physicians}

It was evident in Table 5 that such variables as technical position, department, and employment mode significantly contributed to emotional exhaustion with a total of 5.0\% variance explained in Model $\mathrm{A}_{1}(\mathrm{~F}=3.631, P<$ $0.01)$. Univariate analysis in Model $\mathrm{A}_{2}(\mathrm{~F}=8.543, P<$ $0.01)$, established with job-satisfaction subscales added on basis of Model $A_{1}$, showed that a set of independent variables could jointly accounted for $35.0 \%$ variance of emotional exhaustion, and that job-itself satisfaction $\left(b_{1}=\right.$ $-0.166, P<0.01)$, medical practicing environment satisfaction $\left(b_{1}=-0.096, P<0.05\right)$ and job rewards satisfaction $\left(b_{1}=-0.084, P<0.01\right)$ proved to be significant negative predictors of the emotional exhaustion of physicians, under control of the sociodemographic variables, among which technical position and department were still significant.

Model $\mathrm{B}_{1}(\mathrm{~F}=6.662, P<0.01)$ in Table 5 showed that $10.3 \%$ of the variance in depersonalization could be covered with gender, age, department, education background and employment mode significant. It was known from Model $\mathrm{B}_{2}(\mathrm{~F}=31.95, P<0.01)$, built with job-satisfaction subscales added based on Model $\mathrm{B}_{1}$, that medical practicing environment satisfaction $\left(b_{2}=-0.319, P<0.01\right)$, job rewards satisfaction $\left(b_{2}=-0.150, P<0.01\right)$, and jobitself satisfaction $\left(b_{2}=-0.056, P<0.01\right)$ had significant negative effect on the depersonalization of physicians with $46.1 \%$ variance explained unitedly, under control of the sociodemographic characteristics, among which age, education background and department were still significant.

Table 5 also indicated that when sociodemographic variables merely were brought into Model $\mathrm{C}_{1}(\mathrm{~F}=5.181$, $P<0.01)$, marital status and technical position were significant for accounting for reduced personal accomplishment with $7.7 \%$ variance covered. Out of all job-satisfaction subscales which were added in Model $\mathrm{C}_{2}(\mathrm{~F}=$
27.93, $P<0.01)$, job-itself satisfaction $\left(b_{3}=-0.355, P<\right.$ $0.01)$ rather than other four job-satisfaction factors was identified as significant negative predictor of the reduced personal accomplishment of physicians with a total of $39.8 \%$ variance explained, under control of the sociodemographic characteristics, among which marital status and technical position were still significant.

\section{DISCUSSION}

Firstly, it needs to be pointed out that the working practices and policy-related environment that physicians face are different between urban and rural areas, as well as between public and private medical institutions in China. Our findings are not representative of the situation in rural areas and private medical institutions. Meanwhile, it is seen from sociodemographic structure of study group that the distributions of such variables as age, technical title, and average monthly income form a pyramid shape, which is in accordance with the basic feature of this industry. We also have to note the typical characteristics (largely male, mostly younger than 40 years, and earning less than $\$ 456$ a month) of respondents, when compared with those of other studies.

During the past twenty years, though Chinese government had been trying to explore healthcare system in accordance with conditions, endeavors had failed until a new round of medical reform was executed in 2009. The differences with the old one are that the compensation mechanism for hospitals and doctors will be changed from by drug to by services, and the lifelong relationship system between hospitals and doctors will be replaced by the fixed-term engagement system. According to the Fourth National Health Services Survey (FNHSS, 2008) by Ministry of Health, it seems that this group of physiccians has become focus of being blamed as the scapegoat of failure, and undertaken huge psychological pressures. After the new reform for three years, it is found that the overall burnout was still common and serious, as $87.8 \%$ of the surveyed physicians were exposed in burnout syndrome with over $50 \%$ of them in moderate and severe burnout, which is even higher than the results of another investigation $(n=646)$ [28]. The latter making use of 
Table 5. GLM-univariate analyse with three dimensions on burnout as explained variables.

\begin{tabular}{|c|c|c|c|c|c|c|c|}
\hline \multirow{2}{*}{\multicolumn{2}{|c|}{ Independent variables }} & \multicolumn{2}{|c|}{$\mathbf{E E}$} & \multicolumn{2}{|c|}{ DP } & \multicolumn{2}{|c|}{ RPA } \\
\hline & & $\begin{array}{l}\text { Model A } \\
\text { F, sig. }\end{array}$ & $\begin{array}{l}\text { Model } \mathbf{A}_{2} \\
\text { F, sig. }\end{array}$ & $\begin{array}{l}\text { Model B } \\
\text { F, sig. }\end{array}$ & $\begin{array}{l}\text { Model B } \\
\text { F, sig. }\end{array}$ & $\begin{array}{l}\text { Model } C_{1} \\
\text { F, sig. }\end{array}$ & $\begin{array}{l}\text { Model } C_{2} \\
\text { F, sig. }\end{array}$ \\
\hline \multirow{7}{*}{$\begin{array}{c}\text { Sociodemographic } \\
\text { variables }\end{array}$} & Gender & 2.490 & 1.617 & $7.436^{* *}$ & 3.292 & 0.728 & 0.571 \\
\hline & Age & 2.301 & 1.594 & $12.693^{* *}$ & $7.030^{* *}$ & 2.270 & 0.480 \\
\hline & Marital status & 2.060 & 2.068 & 1.247 & 3.176 & $5.991^{*}$ & $8.136^{* *}$ \\
\hline & Education background & 2.031 & 1.307 & $5.687^{* *}$ & $2.445^{*}$ & 1.077 & 0.731 \\
\hline & Years of service & 0.120 & 0.100 & 2.043 & 1.031 & 0.289 & 0.205 \\
\hline & Technical position & $2.457^{*}$ & $2.476^{*}$ & 1.959 & 1.561 & $8.260^{* *}$ & $9.800^{* *}$ \\
\hline & Department & $3.194^{* *}$ & $2.348^{*}$ & $4.278^{* *}$ & $2.952^{*}$ & 1.611 & 0.944 \\
\hline \multirow{9}{*}{$\begin{array}{l}\text { Job satisfaction } \\
\text { variables }(b)\end{array}$} & Average income (/month) & 0.451 & 0.772 & 0.707 & 0.531 & 0.838 & 0.881 \\
\hline & Employment mode & $6.851^{* *}$ & 1.541 & $6.297^{*}$ & 0.012 & 0.018 & 2.216 \\
\hline & Job-itself satisfaction & & $\begin{array}{l}46.531^{* *} \\
(-0.166)\end{array}$ & & $\begin{array}{l}7.516^{* *} \\
(-0.056)\end{array}$ & & $\begin{array}{l}529.676^{* *} \\
(-0.355)\end{array}$ \\
\hline & Work environment satisfaction & & $\begin{array}{c}0.457 \\
(-0.019)\end{array}$ & & $\begin{array}{c}0.055 \\
(-0.005)\end{array}$ & & $\begin{array}{c}3.526 \\
(-0.033)\end{array}$ \\
\hline & Job rewards satisfaction & & $\begin{array}{l}13.471^{* *} \\
(-0.084)\end{array}$ & & $\begin{array}{l}61.194^{* *} \\
(-0.150)\end{array}$ & & $\begin{array}{c}0.125 \\
(-0.005)\end{array}$ \\
\hline & $\begin{array}{c}\text { Organizational management } \\
\text { satisfaction }\end{array}$ & & $\begin{array}{c}0.838 \\
(-0.024)\end{array}$ & & $\begin{array}{c}0.074 \\
(-0.006)\end{array}$ & & $\begin{array}{c}3.626 \\
(-0.032)\end{array}$ \\
\hline & $\begin{array}{c}\text { Medical practicing } \\
\text { Environment satisfaction }\end{array}$ & & $\begin{array}{l}17.544^{*} \\
(-0.096)\end{array}$ & & $\begin{array}{l}276.702^{* *} \\
(-0.319)\end{array}$ & & $\begin{array}{c}0.365 \\
(-0.009)\end{array}$ \\
\hline & orrected model & $3.63^{* *}$ & $8.54^{* *}$ & $6.66^{* *}$ & $31.95^{* *}$ & $5.18^{* *}$ & $27.93^{* *}$ \\
\hline & Adjusted $\mathbf{R}^{2}$ & 0.050 & 0.350 & 0.103 & 0.461 & 0.077 & 0.398 \\
\hline
\end{tabular}

${ }^{*} P<0.05,{ }^{* *} P<0.01$. ${ }^{*}$ The last category in each sociodemographic variable defined as reference. Abbreviations: EE: Emotional Exhaustion; DP: Depersonalization; RPA: Reduced Personal Accomplishment.

CMBI indicated that $75.7 \%$ of clinical physicians underwent occupational burnout with different levels. In particular, most of the recent studies, for example, among Australian specialist anesthetists [9], merely evaluated separately burnout incidence of practitioners (high, moderate, low) from its three dimensions. Our study further put forward a new evaluation method of four grades on the degree of overall burnout for the first time, which is different from Wang $\mathrm{H}$ et al. that summed average scores of these dimensions. It was compositely indentified with respect to burnout occurrence on each dimension $(>3$ average scores as criteria) rather than only from single dimension or by simply summing. An exploratory study also held that it was not appropriate to directly sum them because burnout has been considered to be a psychological phenomenon measured from three different profiles in space [29].

Concerning the specific aspects of burnout, this study suggested that a high feeling of emotional exhaustion and depersonalization with a low feeling of reduced personal accomplishment was being experienced among Chinese physicians from urban public medical institu- tions. This finding conforms to a survey study among urologists [8], which reported that $50 \%, 38 \%$, and $12 \%$ of them had high emotional exhaustion, high depersonalization, and low personal accomplishment, respectively. We think that this may be attributed to the nature of this career. Generally, clinical physicians are sensitive to burnout due to continuously working with patients deemed as the most principal stressor, whereas they can also simultaneously receive as much as the sense of achievement and recognization from curing patients and saving lives. Besides, it also supports the notion that depersonalization as a kind of response approach to emotional exhaustion is closely related to it in order to protect physicians without suffering over-empathy. Unfortunately, our results do not correspond with other some reports [10,12], which had noted a high level of emotional exhaustion and reduced personal accomplishment with a low level of depersonalization among clinic physicians. This inconsistence might partially stem from the difference of division method besides the sample source or the result of some discrepancies on the medical model and regulation among different countries. 
Our results always demonstrated from Tables $\mathbf{2}$ and $\mathbf{3}$ that less the development level of urban area and higher the grade of public medical institutions, more severe the burnout of physicians was. Only a single study showed that burnout incidence of physicians from the first-grade public hospitals was lower than that from the secondgrade $(\mathrm{OR}=0.67, P<0.01)$ and third-grade $(\mathrm{OR}=0.71$, $P<0.01)$ public hospitals [30], which is basically consistent with our study. In fact, this can be explained by Model $\mathrm{A}_{2}, \mathrm{~B}_{2}$ and $\mathrm{C}_{2}$, displaying that some dimensions of job satisfaction had negatively predictive effects on burnout. We learned depending on the pre-analysis that the satisfaction of the sampled physicians on job-itself, medical practicing environment and job rewards gradually increased from the low-level development area to highlevel development area and also from the third-grade public medical institutions to first-grade public medical institutions. This resulted in an opposite trend on the burnout. In view of the face-to-face in-depth interviews (40 minutes each person) of physicians acquired from these three urban areas by purposive sampling, the same case was also confirmed: physicians from Jingmen city with low-level development and the third-grade medical institutions, experiencing the most serious burnout, expressed evidently greater dissatisfaction with work income and doctor-patient relationship than those from other two groups, through systemic classification of some concepts and attributions. It should be noted that the reason why the group from the third-grade medical institutions practically receiving more absolute income had the above sense, is that current rewards are beneath their expectations caused by heavier workloads and higher technical requirements.

When it came to the correlation between burnout and job satisfaction, each dimension on burnout was found to be negatively related to all subscales of job satisfaction, which had already been confirmed in the previous studies among clinical physicians [10,18]. However, an empirical study pointed that there were no correlations between superiors and colleagues satisfaction, advancement and benefits satisfaction and all three burnout dimensions $(P>0.05)[19]$. From the size of correlation coefficients in Table 4, our analysis tentatively indicated that the associations between job-itself satisfaction, job rewards satisfaction, medical practicing environment satisfaction and burnout were relatively greater. This indicates that physicians less satisfied with these aspects on their jobs tend to report a higher degree of burnout.

Base on the correlation analysis above, this study further signified from Model $A_{2}, B_{2}$ and $C_{2}$ in Table 5 that job-itself satisfaction, job rewards satisfaction, and medical practicing environment satisfaction among job-satisfaction factors had significant predictive impacts on burnout syndrome, under control of the demographic characteristics. The study by Jelena O. et al. similarly con- cluded that job rewards satisfaction noticeably contributed to emotional exhaustion and depersonalization among mental health workers [19], but what doesn't differ with ours is that working climate (including working environment, teamwork support et al.) satisfaction was also identified as a significant predictor of emotional exhaustion $(b=-0.18, P<0.01)$ and personal accomplishment $(b=-0.20, P<0.01)$. It is possible that there is a consequence of difference specific to departments. Unexpectedly, organizational management (covering system construction and leadership behavior) satisfaction, which was mentioned many times by the interviewed physicians, had no effect on any one dimension of occupational burnout. Comparing Model $\mathrm{A}_{2}$ and $\mathrm{A}_{1}$, it is known that the variance with an additional variance of $30.0 \%$ on emotional exhaustion could be explained alone by job satisfaction, and that the variable of employment mode, which became no longer significant in Model $A_{2}$, probably acted on the emotional exhaustion of physicians through job satisfaction. Meanwhile, from a comparison between Model $\mathrm{B}_{2}$ and $\mathrm{B}_{1}$, it is apparent that additional $35.8 \%$ of the variance on depersonalization could be accounted for exclusively by job satisfaction, and that the variables of gender and employment mode were no longer significant in Model $\mathrm{B}_{2}$ and possibly generated an indirect effect on depersonalization via job satisfaction as a mediator. When Model $\mathrm{C}_{2}$ was compared with $\mathrm{C}_{1}$, it is seen that an additional $32.1 \%$ variance on reduced personal accomplishment could be covered by job satisfaction. In spite of this, our results imply that there are other affecting factors expected to be found in the following study on physicians' occupational burnout from the proportion of Adj. $\mathrm{R}^{2}$.

Especially, it was found that job-itself satisfaction played a significant role on each dimension of burnout syndrome among physicians, which needs to be given priority to for the prevention of burnout. The subscale of job-itself satisfaction in measuring instrument covers the appraisal for such elements as person-job matching, autonomy, and professional risk. The Personality-job Fit Theory stated that working enthusiasm depended on the adaptation between individual personality and career environment [24], which was also supported by our result. On the one hand, both heavy workloads as a result of increasing health services demand and dropping job autonomy owing to widespread coverage and gradually strict limitation of medical insurance might result in the unhappiness of physicians and further bring about burnout in China and also among other some countries [2,31]. On the other hand, high professional risk because of frequently confronting life and death in the process of work, regarded as the most important factor related to burnout of physicians, claims to be reduced by intensifying liability insurance to lighten working stress and protect their psychological health. 
In addition, job rewards satisfaction and medical practicing environment satisfaction, which always had significant effect of the first two dimensions of occupational burnout, should also be emphasized as the weakest two aspects in the current. For another example, an investigation $(\mathrm{n}=3182)$ by the Chinese Medical Doctor Association in 2009 displayed that up to $91.9 \%$ of physicians expressed low satisfaction for income, and 39.6\% of physicians weren't satisfied for medical environment with additional $24.0 \%$ of them strongly dissatisfied. The subscale of job rewards satisfaction in measuring instrument includes the appraisal for economic benefits and career development, treated separately as hygiene factor and motivation factor in Two-Factor Theory [24]. Though some studies had affirmed that payments and its equity as an external motivator was one of the significant factors leading to burnout among physicians, career development as an internal motivator may play a more lasting effectiveness of incentive to avoid emotional estrangement during the working. Moreover, the subscale of medical practicing environment satisfaction, which mirrors social system relevant with medical matters, covers the appraisal for doctor-patient relationship and public opinions. Emotional depletion and impersonal attitude of physicians was likely to occur due to the poor doctor-patient relationship, which had been showed by the relevant studies. Through the qualitative interview to physicians, we knew that their psychological depression and low morale might be accounted for by short of favorable communication and declining social status high in the early. Nowadays, it seems that this relationship has grown terribly and goes into a vicious circle when the image of physicians has been demonized to some extent by patients and mass media in China.

\section{LIMITATIONS}

The main limitation was that such measurement tools as job satisfaction and burnout, obtained by modifying the CPJSQ and CMBI, respectively, were the non-standard instruments, and the cross-sectional design usually inferred causal effect with low power. This can be solved if we consider conducting further prospective study by path analysis and structural equation model (SEM), in which other outcomes like working productivity and turnover will also be involved in. Meanwhile, the extrapolation of conclusions would be limited to some extent, as the participants were only chosen from Hubei Province, owing to the constraints of time and convenience; but we were encouraged by the fact that the demographics of the study sample were similar to that of the corresponding group reported in the FNHSS in China. Thirdly, the sample size, based on an estimate of population mean, was relatively small if we took into account the total number of this population; however, it was still sufficient to provide reliable estimates in ANOVA and permit GLM-univariate analysis with statistical significance.

\section{CONCLUSION}

Our study reveals that burnout, especially emotional exhaustion and depersonalization, is greatly common and serious among Chinese physicians from urban public medical institutions, but with high personal achievement. More importance about it needs to be attached to physicians from urban areas with lower-level development and higher-grade medical institutions. Several, but not all dimensions of job satisfaction, which prove to have negatively predictive effects on burnout, should therefore be addressed in order to improve their psychological health. It is hoped that these findings will offer some implications for health-sector managers in the new round of medical reform. Additional research on interventive strategies is essential.

\section{ACKNOWLEDGEMENTS}

This study was funded by the Program for Changjiang Scholars and Innovative Research Team in University (PCSIRT) in China (No. IRT0912), the Young Medical Talents Training Program of Pudong Health Bureau of Shanghai (No. PWRq2011-27), and Health Science and Technology of Pudong Health Bureau of Shanghai (No. PW2011 A-45), which provided a lot of supports in the collection of data and the writing of manuscript. Many thanks must go to these sources of funding. In particular, we would like to heavily acknowledge each physician who completed the questionnaires for their cooperation in the investigation.

\section{REFERENCES}

[1] Williams, E.S., Konrad, T.R. and Schekler, D.P. (2001) Understanding physician's intentions to withdraw from practice: The role of job satisfaction, job stress, mental and physical health. Health Care Management Review, 26, 7-19. doi:10.1097/00004010-200101000-00002

[2] Shirom, A., Nirel, N. and Vinokur, A.D. (2006) Overload, autonomy, and burnout as predictors of physicians' quality of care. Journal of Occupational Health Psychology, 11, 328-342. doi:10.1037/1076-8998.11.4.328

[3] Freudenberger, H.J. (1974) Staff burnout. Journal of Social Issues, 30, 159-165. doi:10.1111/j.1540-4560.1974.tb00706.x

[4] Maslach, C. and Jackson, S.E. (1981) The measurement of experienced burnout. Journal of Occupational Behavior, 2, 99-113. doi:10.1002/job.4030020205

[5] Karasek, R.A. (1979) Job demands, job decision latitude and mental strain: Implications for job redesign. Administrative Science Quarterly, 24, 285-308. doi: $10.2307 / 2392498$

[6] Hobfoll, S.E. and Freedy, J. (1993) Conservation of re- 
sources: A general stress theory applied to burnout. In: Schaufeli, W.B., Maslach, C. and Marek, T., Eds., Professional Burnout: Recent Developments in Theory and Research, Taylor \& Francis, Washington DC.

[7] Demerouti, E., Bakker, A.B. and Nachreiner, F. (2001) The job demands-resources model of burnout. Journal of Applied Psychology, 86, 499-512. doi:10.1037/0021-9010.86.3.499

[8] Bohle, A., Baumgartel, M., Gotz, M.L., et al. (2001) Burnout of urologists in the county of Schleswig-Holstein, Germany: A comparison of hospital and private practice urologists. Journal of Urology, 165, 1158-1161. doi:10.1016/S0022-5347(05)66454-3

[9] Kluger, M.T., Townend, K. and Laidlaw, T. (2003) Job satisfaction, stress, and burnout in Australian specialist anesthetists. Anesthesia, 58, 339-345. doi:10.1046/j.1365-2044.2003.03085.x

[10] Henry, M.K., Timothy, J.E., Mashele, H., et a1. (2007) Career satisfaction, practice patterns and burnout among surgical oncologists. Annals of Surgical Oncology, 11, 3043-3053.

[11] Talma, K. and Avner, H. (2008) Cohen Positive and negative work characteristics associated with burnout among primary care pediatricians. Pediatrics International, 4, 546-551.

[12] Lim, R.C.H. and Pinto, C. (2009) Work stress, satisfation and burnout in New Zealand radiologists: Comparison of public hospital and private practice in New Zealand. Journal of Medical Imaging and Radiation Oncology, 53, 194-199.

[13] Grassi, L. and Magnani, K. (2000) Psychiatric morbidity and burnout in the medical profession: An Italian study of general practitioners and hospital physicians. Psychotherapy and Psychosomatics, 69, 329-334. doi: $10.1159 / 000012416$

[14] Li, C.P., Shi, K. and Luo, Z.X. (2003) An investigation on job burnout of doctor and nurse. Chinese Journal of Clinical Psychology, 3, 171-173.

[15] Wang, H. and Zhang, N. (2008) Analysis on the Status of occupational burnout among doctors. Chinese Journal of Health Psychology, 4, 397-402.

[16] Cordes, C.L. and Dougherty, T.W. (1993) A review and integration of research on job burnout. The Academy of Management Review, 18, 621-656.

[17] Liu, A.F. and Jiang, N.Z. (2007) Review of research on doctor' professional tiredness. Chinese Health Service Management, 9, 620-623.

[18] Nirel, N., Shirom, A. and Ismail, S. (2004) The relation-

\section{LIST OF ABBREVIATIONS}

CPJSQ: Chinese Physicians' Job Satisfaction Questionnaire;

CMBI: Chinese Maslach Burnout Inventory;

GFI: Goodness-of-Fit Index;

NFI: Normed Fit Index; ship between job overload, burnout and job satisfaction, and the number of jobs of Israeli consultants. Harefuah, 143, 779-784.

[19] Jelena, O., Silvia, R. and Lea, Z. (2008) Relation between burnout syndrome and job satisfaction among mental health workers. Croatian Medical Journal, 49, 364-374. doi:10.3325/cmj.2008.3.364

[20] Kalliath, T. and Morris, R. (2002) Job satisfaction among nurses: A predictor of burnout levels. The Journal of Nursing Administration, 32, 648-654. doi:10.1097/00005110-200212000-00010

[21] Visser, M.R., Smets, E.M., Oort, F.J., et al. (2003) Satisfaction and burnout among Dutch medical specialists. Canadian Medical Association Journal, 3, 271-275.

[22] Prosser, S., Tohnson, E., Kuipers, G., et al. (1999) Mental health, burnout and job satisfaction in a longitudinal study of mental health staff. Social Psychiatry and Psychiatric Epidemiology, 34, 295-300. doi: $10.1007 / \mathrm{s} 001270050147$

[23] Shanafelt, T.D., Balch, C.M. and Bechamps, G.J. (2009) Burnout and career satisfaction among American surgeons. Annals of Surgery, 3, 463-471.

[24] Stephen, P.R. (2008) Organization behavior. 12th Edition, Renmin University Press, Beijing.

[25] Yin, W.Q. and Li, Y.L. (2007) Scale establishments on job satisfaction and stability of doctors from public hospitals. MD Thesis, Weifang Medical University, Weifang.

[26] Sun, K., Yin, W.Q., Huang, D.M., et al. (2009) Key influence factors and countermeasures on physicians' satisfaction level. Chinese Health Quality Management, 3, 43-46.

[27] Li, Y.X., Zhang, K. and Zhao, G.X. (2005) Confirmatory factor analysis of job burnout. Psychological Exploration, 4, 70-74.

[28] Wang, H. and Zhang, N. (2008) Analysis on the Status of occupational burnout among doctors. Chinese Journal of Health Psychology, 4, 397-402.

[29] Li, Y.X. and Li, Y.M. (2006) Developing the diagnostic criterion of job burnout. Psychological Science, 1, 148150.

[30] Yin, W.Q., Wang, Z.D., Fan, Y.C., et al. (2008) Analysis of current situation and influencing factors of job burnout of doctors. Chinese Journal of Hospital Administration, 3, 184-187.

[31] Smith, R. (2001) Why are doctors so unhappy? British Medical Journal, 322, 1073-1074. doi:10.1136/bmj.322.7294.1073

CFI: Comparative Fit Index;

IFI: Incremental Fit Index;

RMSEA: Root Mean Square Error of Approximation;

RMR: Root Mean Square Residual;

FNHSS: Fourth National Health Services Survey; SEM: Structural Equation Model. 